\title{
О ПРАВОВОЙ ПРИРОДЕ ПЛАТЕЖНОГО НЕТТИНГА В СОГЛАШЕНИЯХ О ФИНАНСОВЫХ СДЕЛКАХ
}

\author{
А. П. Клементьев \\ Национальный исследовательский университет \\ "Высшая школа эконолики" \\ Поступила в редакцию 17 июня 2019 г.
}

\begin{abstract}
Аннотация: рассматривается платежный неттинг. Он приленяется при осуществлении расчетов по фбинансовыли сделкал, заключаелыли на биржевых площадках и внебиржевол рынке. В частности, положения о платежнол неттинге содержатся в правилах клиринга на организованных торгах, а также в стандартной докулентации, разработанной объединениями проббессиональных участников российских и иностранных фбинансовых рынков для осуществления фбинансовых сделок на двухсторонней основе. В доктринальных источниках присутствуют различные воззрения на вопрос о гражданско-правовой природе неттинга. Анализируются эти источники и сравнивается платежный неттинг со слежныли гражданско-правовыли институтали (отступное, новация и надлежащее исполнение обязательств).

Ключевые слова: неттинг, зачет, взаимозачет, прекращение обязательств, фбинансовые договоры, рамочные договоры.
\end{abstract}

\begin{abstract}
It is the means of settling obligations under financial transactions on foreign exchanges and over-the-counter financial markets. In particular, provisions on payment netting are stipulated in clearing rules for organized trading as well as standard documentation developed by Russian and international associations of financial market participants. Jurisprudence gives various viewpoints on civil law characteristics of netting. Author conducts analysis of these sources and carries out comparison of payment netting with similar civil law instruments (severance pay, novation and due performance of obligations).
\end{abstract}

Key words: netting, set-off, offset, termination of obligations, financial contracts, master agreements.

\section{Правовое регулирование неттинга в России и за рубежом}

Неттинг является механизмом прекращения обязательств, широко используемым при осуществлении финансовых сделок. В настоящее время финансовые рынки невозможно представить без трех основных форм неттинга - платежного, новационного и ликвидационного. Римский институт международного частного права (УНИДРУА) разработал два международных инструмента в рассматриваемой области - Конвенцию о материальных нормах для ценных бумаг, находящихся у посредника, 2009 г. ${ }^{1}$ (далее - Женевская конвенция 2009 г.) и Принципы УНИДРУА

\footnotetext{
${ }^{1}$ URL: http://www.unidroit.org/english/conventions/2009intermediatedsecurities/ convention.pdf
}

(C) Клементьев А. П., 2020 


\section{Вестник ВГУ. Серия: Право}

об осуществлении ликвидационного неттинга, 2013 г. ${ }^{2}$ (далее - Принципы УНИДРУА).

В Женевской конвенции 2009 г. неттинг наряду с зачетом упоминается в контексте прекращения обязательств при наступлении событий обращения взыскания (enforcement events) по соглашениям об обеспечении (collateral agreements) с использованием ценных бумаг. Принципы УНИДРУА предназначены для обеспечения положений о ликвидационном неттинге в условиях банкротства и при иных схожих обстоятельствах.

Важным источником правового регулирования неттинга на уровне Европейского союза выступает Директива 1998/26/EC «Об окончательности расчета в платежных системах и системах расчета по ценным бумагам» ${ }^{3}$. В преамбуле данной директивы указывается, что неттинг должен быть исполнимым во всех странах - участниках ЕC, а результаты его осуществления должны признаваться третьими сторонами. Директива превалирует над законодательствами стран ЕС в части возможности вмешательства в окончательность процедуры неттинга и замены нетто-обязательства требованиями, имевшимися до введения банкротства.

Директива 2002/47/EC «О финансовом обеспечении» ${ }^{4}$ повышает правовую определенность в отношении механизмов применения финансового обеспечения. Директива направлена на защиту положений о неттинге при введении процедур банкротства. При этом прекращение обязательств сторон может проводиться как путем зачета, так и путем неттинга.

В отдельных странах ЕС существуют собственные правовые нормы, закрепленные в Валютном и финансовом кодексе (Франция) и Законе о несостоятельности (Германия).

Регулируют неттинг и документы МНПО. В частности, раздел 2(c) Генерального соглашения Международной ассоциации по свопам и деривативам 2002 г. ${ }^{5}$ содержит положения о неттинге платежей (далее Генеральное соглашение ISDA). Стороны Генерального соглашения могут осуществлять простой и комплексный платежный неттинг (multiple transaction payment netting). Другим примером является Международное генеральное соглашение о валютных сделках 1997 г. ${ }^{6}$ (далее - Генеральное соглашение IFEMA).

${ }^{2}$ URL: https://www.unidroit.org/instruments/capital-markets/netting

${ }^{3}$ Directive 98/26/EC of the European Parliament and of the Council of 19 May 1998 on settlement finality in payment and securities settlement systems // OJ L 166. 11.06.1998. P. 45-50.

4 URL: https://eur-lex.europa.eu/legal-content/EN/TXT/?uri=CELEX\%3A32002 L0047

${ }^{5}$ ISDA Master Agreement 2002. URL: http://mediacommun.ca-cib.com/sitegenic/ medias/DOC/91928/2013-dodd-frank-isda-master-agreements-v2.pdf

${ }^{6}$ International Foreign Exchange Master Agreement 1997. URL: https://www. investopedia.com/terms/i/ifema.asp 
Гражданское право. Гражданский процесс. Арбитражный процесс

В статье будут также рассмотрены Рамочное соглашение для срочных финансовых сделок ${ }^{7}$, разработанное Банковским союзом Германии (далее - Генеральное соглашение DRV), и Рамочное соглашение об операциях на срочных рынках 8 , подготовленное под эгидой Ассоциации французских банков) и Генеральное соглашение FBF соответственно).

Легальная дефиниция неттинга для целей совершения биржевых сделок по российскому праву предложена законодателем в ст. 2 Федерального закона «О клиринге, клиринговой деятельности и центральном контрагенте». К сожалению, окончательной ясности в вопрос о его правовой природе данное определение не вносит, а лишь указывает, что неттинг может осуществляться путем зачета. Согласно закону неттингом является полное или частичное прекращение обязательств, допущенных к клирингу, зачетом и (или) иным способом, установленным правилами клиринга.

В числе основных понятий, используемых в Федеральном законе «О рынке ценных бумаг», термин «неттинг» не упоминается, однако ст. 51.5 содержит требования к содержанию примерных условий договоров на финансовых рынках, среди которых фригурирует порядок определения нетто-обязательства. Как и в случае законодательства о клиринговой деятельности, вопрос о правовой природе неттинга остается также нерешенным. Более того, для целей осуществления операций с ценными бумагами законодатель избегает упоминания о зачете, используя общую формулировку «порядок прекращения обязательств».

Думается, отождествление неттинга и зачета является наиболее очевидным решением проблемы гражданско-правовой природы неттинга. Согласно ст. 410 ГК РФ обязательство прекращается полностью или частично зачетом встречного однородного требования, срок которого наступил либо не указан или определен моментом востребования. Для подобного зачета достаточно воли одной стороны, в то время как зачет требований, срок которых не наступил, допускается только в предусмотренных законом случаях. Статьи 411 и 412 ГК РФ предусматривают случаи недопустимости зачета и порядок осуществления зачета при уступке требования.

\section{Платежный неттинг: понятие и практика применения}

Платежный неттинг (payment netting) или расчетный неттинг (settlement netting) используется для прекращения денежных обязательств со сроком исполнения в одну и ту же дату, имеющих договорный характер и выраженных в одинаковой валюте. Когда наступает дата уплаты валюты, одна из сторон (нетто-должник) перечисляет другой

${ }^{7}$ Rahmenvertrag fur Finanztermingeschafte. URL: https://bankenverband.de/ service/rahmenvertraege-fuer-finanzgeschaefte/deutscher-rahmenvertrag-fuer-finanztermingeschaefte

${ }^{8}$ Convention-Cadre relative aux Opérations de Marché à Terme. URL: http://www. fbf.fr/fr/contexte-reglementaire-international/cadre-juridique/codes-et-conventions/ convention-cadre-fbf-relative-aux-operations-sur-instruments-financiers-a-terme 


\section{Вестник ВГУ. Серия: Право}

стороне (нетто-кредитору) разницу (нетто-сумму) между (а) величиной требований, имеющихся у нетто-кредитора к нетто-должнику и (б) величиной требований нетто-должника по отношению к нетто-кредитору, причем вплоть до момента наступления срока исполнения требования по сделкам не прекращаются и существуют в неизменном виде. Платежный неттинг может осуществляться на двухсторонней или многосторонней основе.

Примером двухстороннего платежного неттинга являются «Примерные условия договора о срочных сделках на финансовых рынках» 2011 г., утвержденные СРО «Национальная ассоциация участников фондового рынка» (далее - Примерные условия). На основании Примерных условий кредитные организации разрабатывают собственные формы рамочных соглашений о неттинге для совершения сделок с производными финансовыми инструментами (срочных сделок). Примерные условия предусматривают возможность применения сразу двух разновидностей платежного неттинга - простого и комплексного. Для распространения Примерных условий на отношения сторон срочных сделок требуется заключение генерального соглашения о срочных сделках на фринансовых рынках, частью которого являются Примерные условия.

Согласно п. 3.5 Примерных условий обязательства в одной и той же валюте и по одной и той же сделке с исполнением в одинаковую дату автоматически прекращаются в такую дату. Если сумма обязательства одной стороны превышает сумму обязательства другой стороны, обязательство первой стороны прекращается в части, равной сумме обязательства другой стороны, а обязательство последней прекращается полностью. В п. 5.5. Приложения 1 к Примерным условиям предусмотрено положение о комплексном платежном неттинге, который является аналогом платежного неттинга, но применяется для обязательств из разных сделок.

До публикации Примерных условий участники российского финансового рынка часто использовали собственные формы соглашений о неттинге, например договоры об общих условиях совершения валютных конверсионных сделок ${ }^{9}$, предоставления межбанковских кредитов ${ }^{10}$ и соглашения о сотрудничестве на межбанковском денежном и валютном рынке в рублях и иностранной валюте ${ }^{11}$.

140 Самостоятельной разновидностью неттинга является новационный неттинг, пример использования которого присутствует в упомянутом выше Генеральном соглашении IFEMA. Как указано в п. 3.3 Соглашения, при заключении сделки с валютой, в результате которой появляется обязательство по поставке той же валюты и в ту же дату, что и по ранее заключенной сделке, оба обязательства заменяются новым обязательством по поставке валюты в размере разницы между требованиями. Не-

${ }^{9}$ Определение Верховного Суда РФ от 10 июля 2017 г. № 305-ЭС17-5409 по делу № A40-36922/2016.

10 Постановление Президиума ВАС РФ от 21 января 2014 г. № 12825/13 по делу № A72-3615/2012.

${ }^{11}$ Решение МКАС при ТПП РФ от 21 февраля 2001 г. по делу № 37/2000. 
Гражданское право. Гражданский процесс. Арбитражный процесс

трудно видеть, что новационный неттинг во многом схож с платежным. Различие между ними состоит в одном обстоятельстве - при новационном неттинге обязательства прекращаются не в дату их исполнения, а в момент заключения каждой последующей сделки ${ }^{12}$.

Таким образом, в ходе новационного неттинга происходит замена заключенных сделок новым контрактом ${ }^{13}$, причем эта замена осуществляется каждый раз с заключением более поздней сделки.

Согласно п. 340 Глоссария Банка для международных расчетов (далее - Глоссарий БМР) соглашение о неттинге новаций предусматривает исполнение индивидуальных форвардных договорных обязательств (например, валютных договоров) в момент их подтверждения и замену новыми обязательствами, составляющими часть одного соглашения. Суммы, причитающиеся по исполненному договору, будут добавлены к текущим остаткам, взаимно причитающимся сторонам в каждой валюте по каждой будущей дате валютирования ${ }^{14}$.

Наиболее сложной разновидностью неттинга с точки зрения механизма осуществления и юридической квалификации является ликвидационный неттинг. Он используется для прекращения обязательств с разными сроками исполнения и не требует их «однородности». Кроме того, проведение ликвидационного неттинга обусловлено нарушением обязанностей одной из сторон, что может выражаться в просрочке поставки или платежа, ухудшении финансового положения, начала процедур банкротства или иными событиями ${ }^{15}$.

\section{Платежный неттинг и иные способы прекращения обязательсть}

Представляется, что платежный неттинг соответствует таким критериям зачета, как встречность и однородность, однако камнем преткновения в данном случае выступает односторонний характер гражданско-правового зачета. Таким образом, представляется возможным согласиться c А. С. Селивановским и Р. А. Файзуллиным, указавшими на ошибочность отождествления неттинга и зачета ${ }^{16}$. Такой вывод представляется обоснованным в отношении платежного неттинга на основе рамочных соглашений на внебиржевом рынке, несмотря на частое синонимичное

${ }^{12}$ A Glossary of Terms Used in Payments and Settlement Systems. URL: https:// www.bis.org/cpmi/glossary_030301.pdf

${ }^{13}$ CM.: King M. J. Back Office and Beyond: A Guide to Procedures, Settlements and Risk in financial markets New York [etc.] : Harriman House, cop., 2003. P. 115.

${ }^{14}$ Cм.: Derham R. Op. cit. P. 561 ; Буркова A. Правовые основы неттинга // Банковское право. 2010. № 2. С. 8.

${ }^{15}$ См. более подробно: Липовцев B. H. Lex mercatoria и рынок ценных бумаг новеллы правового регулирования // Бизнес в законе. 2012. № 1. С. 116.

${ }^{16}$ См.: Селивановский А. С. Зачет, взаимозачет, неттинг? // Хозяйство и право. 2009. № 9. С. 61 ; Файзуллин Р. А. Вопросы регулирования клиринговой деятельности на рынке ценных бумаг // Предпринимательское право. Приложение «Право и Бизнес». 2014. № 2. С. 53. 


\section{Вестник ВГУ. Серия: Право}

использование терминов «неттинг» и «зачет» в судебной ${ }^{17}$ и арбитражной практике $\mathrm{e}^{18}$.

При этом у клиринговых организаций существует теоретическая возможность предусмотреть в своих внутренних правилах осуществление неттинга путем зачета, как это предусмотрено в ст. 2 Федерального закона «О клиринге, клиринговой деятельности и центральном контрагенте». Однако такая конструкция вряд ли является возможной в силу высокой скорости и автоматизации биржевых расчетов, не позволяющих регулярно направлять уведомление о зачете. Правила клиринга Небанковской кредитной организации - центрального контрагента «Национальный клиринговый центр» предусматривают понятия «нетто-обязательство участника клиринга" и «нетто-требование участника клиринга», которые выявляются самой клиринговой организацией и представляют собой превышение требований участника клиринга над требованиями клиринговой организации и наоборот. При этом для выявления этих требований «классический» зачет не осуществляется.

Если обратиться к п. 3.5 Примерных условий, можно обнаружить акцент на прекращении обязательств при формулировании положений о платежном неттинге. Целесообразно провести сравнительный анализ неттинга и других способов прекращения обязательств. Помимо зачета в ГК РФ упоминаются и другие способы прекращения. Для целей определения правовой природы платежного неттинга интерес представляют надлежащее исполнение обязательств (ст. 408), отступное (ст. 409) и новация (ст. 414).

Надлежащее исполнение является наиболее «естественным» способом прекращения обязательства и подразумевает осуществление действий (или, наоборот, отказ от их осуществления) должником в соответствии с изначальными условиями обязательства. Генеральное соглашение DRV ним не происходит никакого движения денежных средств или ценных бумаг в изначально намеченную дату исполнения.

Если задуматься о возможности квалификации платежного неттинга в качестве способа прекращения обязательств путем предоставления отступного, то можно прийти к следующим выводам. Во-первых, нерешенной остается проблема нулевой разницы между требованиями. Во-вторых, в случае неттинга обязательства прекращаются не с момента уплаты отступного в форме нетто-суммы, как того требует ГК РФ, а

${ }^{17}$ Определение Верховного Суда РФ от 1 марта 2017 г. № 309-КГ17-21 по делу № A76-30784/2015 ; постановление ФАС Восточно-Сибирского округа от 19 апреля 2011 г. по делу № А58-79/2010.

${ }^{18}$ Решение МКАС при ТПП РФ от 21 февраля 2001 г. по делу № 37/2000. 
Гражданское право. Гражданский процесс. Арбитражный процесс

в изначально оговоренную дату расчетов. Таким образом, обязательства одной из сторон прекратятся полностью, даже если уплата разницы не будет осуществлена контрагентом. Следовательно, квалификация неттинга в качестве отступного так же имеет изъяны, как и в качестве надлежащего способа исполнения.

Целесообразно провести также сравнительный анализ платежного неттинга и новации, поскольку в результате неттинга обязательство по уплате разницы «заменяет» изначальные обязательства сторон по поставке валюты. Согласно ст. 414 ГК РФ обязательство прекращается соглашением сторон (новация), если иное не установлено законом или не вытекает из существа отношений. Данная формулировка стала результатом реформы гражданского законодательства. При этом для совершения новации между сторонами обязательства заключается соглашение о новации ${ }^{19}$.

При рассмотрении неттинга в качестве новации не только сохраняется проблема «нулевой разницы», но и появляется новое затруднение несоответствие момента заключения соглашения о новации требованиям законодательства. Фактически стороны заключают договор о неттинге еще до заключения самих сделок, обязательства по которым будут прекращаться неттингом. В доктрине высказывалось мнение о том, что для осуществления новации необходимо наличие фактического состава, элементами которого являются существование прежнего обязательства, наличие уже упомянутого соглашения о новации и возникновение нового обязательства ${ }^{20}$. В случае неттинга последовательность элементов юридического состава нарушена, что противоречит буквальной трактовке положений ст. 414 ГК РФ.

Признаком новации можно также считать намерение обновить обязательство (animus novandi) ${ }^{21}$. Согласно п. 2 Информационного письма Президиума ВАС РФ от 21 декабря 2005 г. № 103 «Обзор практики применения арбитражными судами статьи 414 Гражданского кодекса РФ» обязательство прекращается новацией тогда, когда воля сторон определенно направлена на замену существовавшего между ними первоначального обязательства другим обязательством. Наличие данного признака animus novandi используется и для отграничения новации от изменения договора и прекращения обязательств предоставлением отступного 22.

${ }^{19}$ Как указывает М. А. Егорова, соглашение о новации является сделкой, а сама новация выступает правовым механизмом прекращения обязательств (см.: Егорова M. А. Правовая природа соглашения о новации // Юридический мир. 2011. № 5. C. 35).

${ }^{20}$ См.: Грачев В. В. Новация вексельного долга // Законы России : опыт, анализ, практика. 2015. № 10. С. 70-74.

${ }^{21}$ См.: Виндшейд Б. Об обязательствах по римскому праву. СПб., 1875. С. 253 ; Дернбург Г. Пандекты. Т. 2 : Обязательственное право. 3-е изд. М., 1911. С. 161 ; Мейер Д. И. Русское гражданское право. М., 1997. Ч. 2. С. 342.

${ }^{22}$ См.: Павлов А. А. Условия и последствия новации // Вестник ВАС РФ. 2006. № 8. C. 9. 


\section{Вестник ВГУ. Серия: Право}

Наличие такого намерения выступает критерием разграничения новации и изменения обязательства ${ }^{23}$. Неизвестно, насколько можно считать уплату нетто-суммы по финансовым сделкам полноценным «обновлением» обязательств, поскольку некоторые финансовые сделки (например, форвардные валютные договоры и конверсионные сделки) подразумевают обычную поставку валюты к определенному сроку. При неттинге подобных сделок происходит изменение уплачиваемых сторонами сумм, но существо обязательства и дата расчетов остаются неизменными.

\section{Платежный неттинг как способ расчетов и договорный зачет}

Л. Г. Ефимова определяет неттинг как «разновидность расчетов, осуществляемых при участии клиринговой организации с помощью сальдо взаимных требований участников клиринга» ${ }^{24}$. Данная позиция согласуется и со взглядами Л. Н. Новоселовой на природу зачета как метода организации взаимных расчетов ${ }^{25}$. Как указывает Н. Ю. Ерпылева, расчетные отношения включают в себя фрактически и юридически значимые действия, направленные на исполнение денежного обязательства (погашение денежного долга) в наличной и безналичной формах ${ }^{26}$.

В настоящее время ст. 862 ГК РФ предусматривает открытый перечень форм безналичных расчетов, включающий расчеты в установленных в соответствии с ним банковскими правилами формах и применяемыми в банковской практике обычаями делового оборота. На первый взгляд, предусмотренная законодателем ссылка на банковские правила и обычаи является хорошим подспорьем для обоснования «расчетной» природы неттинга. Примерные условия широко используются кредитными организациями, а в их разработке принимало участие одно из крупнейших банковских объединений ${ }^{27}$.

Однако при более детальном изучении положений о неттинге, изложенных в упомянутых выше генеральных соглашениях, прослеживается высокая вероятность уплаты разницы в виде нетто-суммы с использованием традиционного способа расчетов, например платежных поручений. Представляется, что для квалификации платежного неттинга в качестве самостоятельного расчетного обязательства необходимо, чтобы стороны

${ }^{23}$ См.: Шеббас П. А. Новация и изменение обязательства // Вестник гражданского права. 2019. № 2. С. 61-112.

${ }^{24}$ Ебилова Л. Г. Договоры об организации расчетов : понятие, виды, система, правовая природа // Гражданское право и современность : сб. статей, посвященный памяти М. И. Брагинского / под ред. В. Н. Литовкина, К. Б. Ярошенко. М., 2013.

${ }^{25}$ См.: Новоселова Л. А. Денежные расчеты в предпринимательской деятельности. М., 1996. С. 117.

${ }^{26}$ См.: Ерпылева Н. Ю. Международное банковское право. М., 2012. С. 437.

${ }^{27}$ См.: Кормош Ю. И. Стандартизация внебиржевых срочных сделок как антикризисная мера для российского финансового рынка // Труды института государства и права Российской академии наук. Совершенствование законодательства путь к преодолению мирового фринансового кризиса. М., 2010. № 4. С. 173-202. 
Гражданское право. Гражданский процесс. Арбитражный процесс

отношений не прибегали к поименованным способам расчетов. Тем не менее с экономической точки зрения озвученный подход представляется удачным, поскольку платежный неттинг позволяет снизить так называемый «расчетный» или риск, возникающий при расчетах на фринансовом рынке ${ }^{28}$.

Таким образом, платежный неттинг не может быть квалифицирован не только в качестве одного из поименованных в ГК РФ способов прекращения обязательств, но и в качестве самостоятельного способа расчетов. К счастью, указанные способы исполнения обязательств и расчетов не формируют numerus clausus. Статья 407 ГК РФ указывает, что обязательство прекращается полностью или частично не только по основаниям, предусмотренным непосредственно законодательством, но и договором. Следовательно, стороны гражданско-правовых договоров вольны сконструировать самостоятельные способы их прекращения.

Одним из таких способов является взаимозачет, известный как договорный зачет. Как указывает М. И. Брагинский, к такому зачету не применяются ограничения, установленные в ст. 410 ГК РФ ${ }^{29}$. Договор, формулирующий правила проведения взаимозачета и предусматривающий перечень включаемых в него обязательств известен как «договор о зачете» или «договор о сторнировании» ${ }^{30}$. В условиях проведения сделок в РФ использование договорного зачета основывается также на ст. 411 ГК РФ, которая позволяет ограничивать односторонний зачет договором, и на ст. 421 ГК РФ, закрепляющей принщип свободы договора ${ }^{31}$.

Участники взаимозачета переводят друг другу только разницу, которая образуется в результате суммирования и вычета соответствующих требований сторон ${ }^{32}$. Для удобства и устранения терминологической путаницы в этом вопросе А. В. Егоров предлагает ввести в научный оборот понятие зачета в «узком» смысле ${ }^{33}$ и зачета в «широком» смысле, под которым можно понимать любое уменьшение встречных обязательств сторон, происходящее как в одностороннем порядке, так и на основании договора ${ }^{34}$. Таким образом, зачет в широком смысле будет выступать «родовым» термином по отношению к зачету и взаимозачету.

Приверженцами отождествления неттинга и взаимозачета являются и другие ученые. В частности, А. С. Селивановский указывает, что в общепринятом смысле под неттингом понимают метод определения размера обязательств путем агрегирования, комбинирования, взаимозаче-

${ }^{28}$ См.: Derham R. Op. cit. P. 536.

${ }^{29}$ См.: Брагинский М. И., Витрянский В. В. Договорное право : общие положения. М., 1997. С. 363.

${ }^{30}$ См.: Селивановский А. С. Указ. соч. С. 57-61.

${ }^{31}$ См.: Буркова А. Зачет как способ прекращения обязательств // Юрист. 2010. № 5. C. 37.

${ }^{32}$ См.: Буркова А. Правовые основы неттинга. С. 7.

${ }^{33}$ Н. Г. Вавин для тех же целей использовал термин «зачет в тесном смысле» (см.: Вавин Н. Г. Зачет обязательств. 2-изд., испр. и доп. М., 1914).

${ }^{34}$ См.: Егоров А. В. Зачет - сделка или результат? // ЭЖ-Юрист. 2000. № 52. 


\section{Вестник ВГУ. Серия: Право}

та двух или более обязательств ${ }^{35}$. В. В. Драгунов полагает, что неттинг является специфическим подвидом договорного зачета с комплексным механизмом реализации, часто сочетающим в себе элементы различных договоров ${ }^{36}$. Р. С. Куракин определяет неттинг как процедуру проведения взаимозачета встречных обязательств по биржевым сделкам, при которой две стороны в рамках соглашения по определенному перечню встречных обязательств прекращают встречные однородные обязательства с одновременным возникновением нового обязательства на сумму оставшегося обязательства ${ }^{37}$.

Поскольку определения взаимозачета в ГК РФ не содержится, поэтому четкие критерии и дефиницию взаимозачета может установить исключительно доктрина и судебная практика. В одном из судебных дел указывалось, что взаимозачетом является «особый вид ремиссионной сделки, в основе которой лежит механизм зачета, но действительность которой связана с применением к ней принципа свободы договора (п. 2 ст. 421 ГК РФ), предусматривающей возможность заключения гражданско-правового договора как предусмотренного, так и не предусмотренного законом или иными правовыми актами, а не с применением норм о зачете, регламентированных главой 26 ГК РФ» ${ }^{38}$.

Нередко неотъемлемой частью отношений по взаимозачету выступает акт о взаимозачете ${ }^{39}$, посредством которого определяется размер нетто-суммы. Ни Примерные условия, ни Генеральное соглашение ISDA и IFEMA составление такого акта не предусматривают ${ }^{40}$. Согласно Генеральному соглашению DRV сторона, являющаяся банком, обязана уведомить своего контрагента о результатах неттинга, однако такое уведомление осуществляется постфактум и никоим образом не требует согласия контрагента.

В связи с этим наиболее обоснованным выглядит мнение А. Ю. Бурковой, в соответствии с которым неттинг рассматривается в более широ-

${ }^{35}$ См.: Селивановский А. С. Указ. соч. С. 59.

${ }^{36}$ См.: Драгунов В. В. Односторонний и договорный зачет : российская практика и международный опыт // Право и экономика. 2003. № 11.

$146{ }^{37}$ См.: Куракин Р. С. Правовое регулирование биржевого срочного рынка. М., 2010. С. 110. К числу сторонников квалификации неттинга в качестве взаимозачета можно также отнести А. Бычкова (см.: Бычков А. Договор процентного свопа // ЭЖ-Юрист. 2014. № 26. С. 12).

38 Постановление Арбитражного суда Волго-Вятского округа от 9 февраля 2015 г. № Ф01-6090/2014 по делу № А28-3276/2014.

39 Постановление ФАС Западно-Сибирского округа от 13 октября 2011 г. по делу № А75-4230/2010, постановление ФАС Восточно-Сибирского округа от 17 фревраля 2009 г. № А19-7871/08-30-04АП-3049/08-Ф02-275/09 по делу № А197871/08-30, постановление Президиума ВАС РФ от 28 июня 2011 г. № 17500/10 по делу № А41-19368/08.

${ }^{40}$ Хотя п. 3(3) Генерального соглашения DRV предусматривает обязанность банка направить контрагенту сообщение о сумме, которая образуется в результате неттинга. 


\section{Гражданское право. Гражданский процесс. Арбитражный процесс}

ком контексте в качестве договорного способа прекращения обязательств, предусмотренного соглашением сторон ${ }^{41}$.

При таком подходе платежный неттинг выступает в качестве способа прекращения обязательств sui generis, порядок и последствия использования которого могут быть установлены как в договорной документации, так и в правилах клиринга. В пользу данного подхода говорит не только неопределенность требований, предъявляемых к взаимозачету, но и уникальность самих финансовых сделок, обязательства по которым прекращаются путем неттинга.

В результате проведенного анализа положений о неттинге, содержашихся в российских и зарубежных рамочных соглашениях о сделках на финнансовых рынках, можно прийти к следующим выводам. С точки зрения законодательства и доктрины возможна квалификация платежного неттинга в качестве предусмотренного ГК РФ способа прекращения гражданско-правовых обязательств, особой разновидности расчетов или взаимозачета. Каждый из данных подходов имеет свои недостатки. Наиболее удачным, с точки зрения автора, подходом к квалификации платежного неттинга выступает его рассмотрение в качестве непоименованного (sui generis) в ГК РФ способа прекращения обязательств, возникающих из финансовых договоров.

\footnotetext{
${ }^{41}$ См.: Буркова А. Правовые основы неттинга. С. 7.
}

Национальный исследовательский университет "Высшая школа эконоликu»

Клелентьев А. П., ассистент департалента обших и межотраслевых юридических дисииплин фбакультета права

E-mail: aklementiev@hse.ru
National Research University "Higher School of Economics"

Klementyev A. P., Assistant of the General and Interdisciplinary Legal Studies Department Faculty of Law

E-mail: aklementiev@hse.ru 